
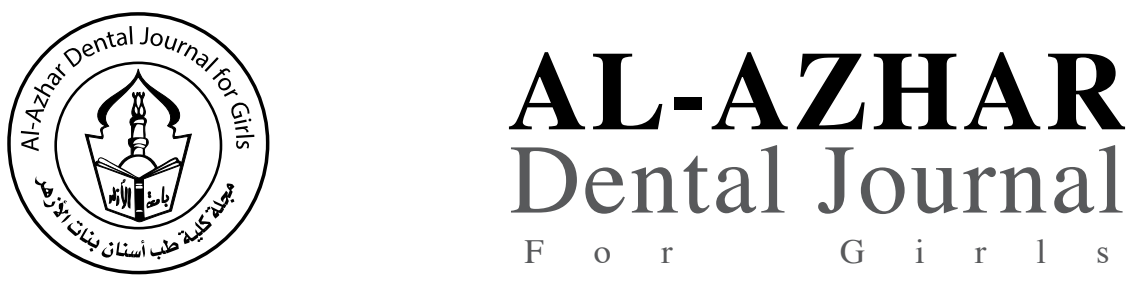

The Official Publication of The Faculty of Dental Medicine For Girls, Al-Azhar University Cairo, Egypt.

ADJ-for Grils, Vol. 3, No. 4, October (2016) - PP. 287:292

\title{
The Effect of Two Different Denture Base Materials on Retention of Complete Denture in Severely Resorbed Lower Ridge Cases
}

\author{
Eman Soror Sayed Ebrahim ${ }^{(1)}$, Amany Ahmed Abdel-Fattah ${ }^{(2)}$, Shereen Mohamed Mohamed Kabee ${ }^{(3)}$
}

Codex : 05/1610

dentaljournal.forgirls@yahoo.com

\begin{abstract}
Aim of the study: to compare between two different denture base materials regarding their effect on the retention of complete dentures in patients with severely resorbed lower edentulous ridges. Material \&methods: seven completely edentulous patients with age ranged between 55 and 65 years were selected for this study; each patient received three types of lower dentures to use it for four months, in addition to one week in between as a washing period before wearing the new one. Denture bases classified into three groups, heat cured acrylic resin denture base (Group I), heat cured acrylic resin denture base where the lower denture was lined by soft liner material (Group II) and a combination base of heat cured acrylic resin and Co-Cr denture base (Group III). Retention was evaluated after one month and three months from dentures delivery. Results: the results of this study revealed that a significant differences between group I, group II and group III denture bases during the follow up study period after one month, and non-significant differences between group I, group II and group III denture bases during the follow up study period after three months. Conclusion: from this study it is concluded that the $\mathrm{Co}-\mathrm{Cr}$ denture base and Conventional heat cure acrylic resin denture base lined with soft liner material could be used as alternative treatment modalities to conventional heat cure acrylic resin denture bases in complete edentulous cases suffering from severely resorbed lower ridges.
\end{abstract}

\section{INTRODUCTION}

Residual ridge resorption is a complex biophysical process and a common occurrence following extraction of teeth. Ridge atrophy is most dramatic during the first year after tooth loss followed by a slower but more progressive rate of resorption thereafter. The reduction of the

\section{KEYWORDS}

Residual alveolar ridge,

Soft liner,

Denture base materials

1. Dentist at Medical Affairs for Girls, Al Azhar University.

2. Professor of Removable Prosthodontics, Vice Dean of Faculty of Dental Medicine for Girls, Al-Azhar University.

3. Lecturer of Removable Prosthodontics, Faculty of Dental Medicine for Girls, Al Azhar University. 
alveolar bone is a chronic, progressive, irreversible and disabling disease that causes physical, psychological and economic problems ${ }^{(1)}$. Decreased physical activity, lowered estrogens, diet, race and heredity may all play a role in age-related bone loss, which is also seen in the mandible than the maxilla ${ }^{(2)}$.

The best way to manage the problem of residual ridge resorption is by using every means to prevent it. Clinicians must try to retain residual roots whenever possible. Certain general principles must be kept in mind during fabrication of complete dentures, which will help to reduce the stress transmission and help to preserve the alveolar ridge. This may be achieved by having broad area of coverage under the denture base to reduce the force per unit area. ${ }^{(3)}$ Impression technique in patients with severely resorbed ridges, is challenging. Lack of ideal amount of supporting structures decreases support and the encroachment of the surrounding mobile tissues on to the denture border reduces both stability and retention. Thus the main aim of the impression procedure is to gain maximum area of coverage. In mandibular ridge, obtaining a fairly long retromylohyoid flange helps to achieve a better border seal and retention ${ }^{(4)}$.

Conventional heat cure PMMA (Polymethylmethaacrylate) is the most commonly used denture base resin, due to its excellent appearance, easy processing and repair. Advantage of heat-cured PMMA includes; it is nontoxic, insoluble, inert in oral fluid, esthetically accepted, easy processing and repair, adequate shelf life and inexpensive ${ }^{(5)}$.

Using metal bases for the mandibular denture help in preservation of remaining residual ridge by optimal distribution of applied load over an increased area. Furthermore, it improved patient comfort because of smooth tissue surface, better support, retention and stability because of close adaptation, prevention of chronic soreness from hard denture surface ${ }^{(6)}$.
The advantages of metallic denture base are biocompatibility, hypoallergic effect with healthy appearing supporting tissues and added strength for easily fractured dentures. Moreover, the metallic denture base facilitate fabrication of stable narrow dentures that are designed to avoid contact with disrupting muscle forces and sometimes facilitate avoidance of surgical procedures such as frenum reposition. Additionally, patients perceive natural feeling from thin base, which may also contribute to additional denture stability ${ }^{(7)}$.

A prolonged and close contact between the edentulous oral mucosa and inner surface of complete denture, associated with the transmission of occlusal force lead to tissue diseases, bone resorption and pain in short and long term. In order to overcome these difficulties and improve the biological integration, the setting of a polymeric soft liner into the hard denture base allow a limited transmission of forces and pressures generated during mastication and lead to relief of oral mucosal pain ${ }^{(8)}$.

Soft liner acts as shock absorber and tissue conditioners that can reduce and distribute occlusal forces to the underlying oral structures during function while enhancing patient comfort. Also it may reduce the residual ridge resorption by reducing impact force in the load bearing area in thesupporting structure during function. It produce a cushioning effect and so constitute an attractive medical response for elderly patients ${ }^{(8,9)}$.The aim of this study was to compare between two different denture base materials regarding their effect on the retention of complete dentures in patients with severely resorbed lower edentulous ridges.

\section{MATERIALS AND METHODS}

Seven completely edentulous patients were selected. The patients had completely edentulous maxillary and mandibular ridges where their mandibular ridges were severely resorbed, covered with firm and healthy mucosa free from any signs of inflammation, ulceration or flappy tissues. All patients 
accepted this dental treatment and informed about the steps of this study and signed a written informed consent.

Each patient received three dentures, complete denture with heat cured acrylic resin denture base (group I), complete denture with heat cured acrylic resin denture base lined by soft liner (group II) and complete denture with $\mathrm{Co}-\mathrm{Cr}$ denture base (group III).

Dentures were constructed following the conventional clinical and laboratory techniques. After group I denture delivery all patients were instructed to use their dentures for one month as minimal period after delivery. Retention was evaluated after one month and three months from delivery of group I dentures.

After resting period for one week soft liner was applied to the fitting surface of group I dentures after reduction of the tissue surface of the dentures. The mixed soft liner was applied to the tissue surface of the denture, with a wood spatula and was allowed to flow evenly as a thin layer to cover the entire impression surface area of the denture and its borders. The denture was inserted in the patient's mouth then the patient was instructed to close in centric occlusion to stabilize the denture until setting of the soft liner. When the soft liner set, as it changed into a rubbery consistency, the denture was removed from the patient mouth and the excess material was removed using No 15 surgical blade lancet.

The tissue surface of the denture was inspected for continuity of the soft liner layer. Pressure areas should be relived, areas of under extensions were corrected by adding more material and areas of over extension were reduced. Retention was evaluated after one month and three months from dentures delivery.

$\mathrm{Co}-\mathrm{Cr}$ dentures in combination with the heat cured acrylic resin were constructed following as basic method for metal construction, after resting period for one week Co-Cr dentures delivered to all patients and the patients were instructed to use Co$\mathrm{Cr}$ denture for one month as minimal period after delivery. Retention was evaluated after one month and three months from delivery of $\mathrm{Co}-\mathrm{Cr}$ dentures.

\section{1- Retention evaluation:}

Retention was measured by Universal Testing Machine, which use a computer software package to deliver a vertical dislodging force at across - head speed of $10 \mathrm{~mm} / \mathrm{min}$ to each denture sample from the vertical direction. The retentive forces required to separate the acrylic resin denture were measured after one and three months from delivery and the applied force was expressed in Newton (N).

\section{RESULTS}

All patients sharing in this study were well motivated to complete the follow-up schedule. There were three study groups of denture bases and the time factor considered as a sub group to compare between retention of two different denture bases at one month and three months. Descriptive statistics of the retention results measured in $(\mathrm{N})$ for all groups as function of time and their statistical analysis were tabulated in table (1) and graphically illustrated in figures (1).

Table (1) Retention results (Mean $\pm S D$ ) for all groups as function of time

\begin{tabular}{|c|c|c|c|c|c|}
\hline \multirow{2}{*}{ Variable } & \multicolumn{3}{c|}{ Denture type } & \multirow{2}{*}{$\begin{array}{c}\text { Statistics } \\
\text { P value }\end{array}$} \\
\cline { 3 - 6 } & Group I & Group II & Group III & $0.009 *$ \\
\hline \multirow{2}{*}{ Time } & 1 month & $2.62 \pm 0.89$ & $4.05 \pm 1.4$ & $2.68 \pm 0.39$ & $0.6746 \mathrm{~ns}$ \\
\cline { 2 - 6 } & $\mathbf{3}$ months & $3.41 \pm 0.73$ & $3.47 \pm 0.88$ & $3.84 \pm 1.1$ & \\
\hline Statistics & P value & $0.0001 *$ & $0.382 \mathrm{~ns}$ & $0.01 *$ & \\
\hline
\end{tabular}

Ns; non-significant $(P>0.05) *$; significant $(P<0.05)$ 


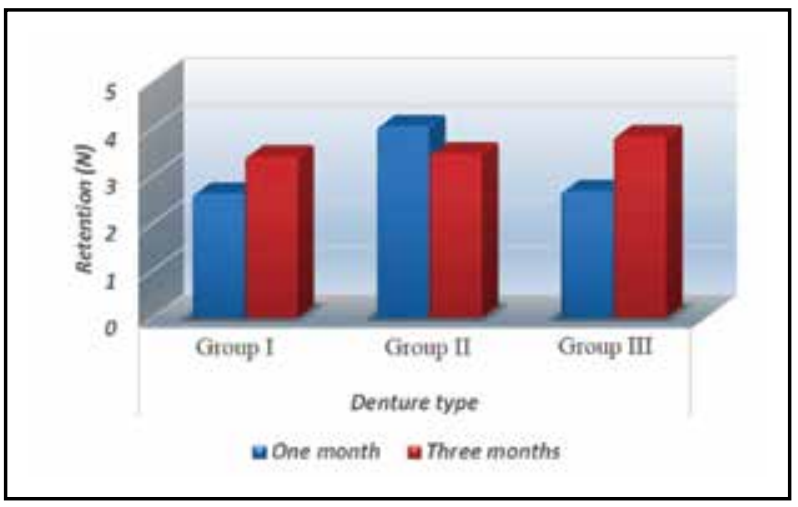

Fig. (1)

\section{DISCUSSION}

This study dealt with the use of two different denture base materials; Conventional heat cured acrylic resin lined with soft linear and metallic denture base and their effect on the retention of complete denture. Complete denture should be retentive to achieve its goals as speech, mastication, esthetics and patient comfort.

Seven patients were selected four males and three females for this study. It was found that females are more anxious about their oral condition and more cooperative in following good oral hygiene instruction than males ${ }^{(10)}$.The age of the selected patient ranged between 55-65 years. Very old patients were excluded because there are many factors that would complicate denture treatment process of aged patients such as decreased neuromuscular coordination, reduce ability to sense where the mandible is in relation to maxilla (oral awareness). Besides, this age (50-60 years) had presence of severely resorbed ridge ${ }^{(11)}$.

In the present study, the edentulous mandibular ridge were selected rather than the maxillary ridges, since, the amount of bone resorption is generally greater in mandible, which implies that the mandibular denture usually possess great clinical problem for the patient and the prosthodontics ${ }^{(12)}$. The edentulous ridge had normal morphology and cover with firm healthy mucosa to ensure favorable conditions for prosthetic procedures. These patients had no prosthetic experience in denture wearing to eliminate the expected adaptation of the muscles to the denture that mask the results ${ }^{(13)}$.

Patients were selected with normal tongue size to avoid the effect of abnormal tongue size on stability of the lower denture. In addition large tongue size is considered as an obstacle during retention measurement ${ }^{(14)}$.

Conventional denture base lined with soft liner material was used as a treatment alternative that aid in increasing retention and stability when conventional denture therapy is inadequate. The liner materials were applied to the fitting surface of dentures to achieve more equal force distribution, reduce localized pressure and improve denture retention by engaging undercuts ${ }^{(15)}$.

$\mathrm{Co}-\mathrm{Cr}$ alloy is the most commonly used for casting metallic dentures. They are an economically important alternative to gold alloy, owing to decreased cost and improved mechanical properties, metal base denture display excellent strength -to- volume ratios and can be cast in thin sheets maintaining rigidity and fracture resistance ${ }^{(16)}$.

In the current study, the finished denture was inserted in the patient's mouth for fine adjustment of occlusion and border extension because any occlusal interference would impair the retention and stability of the denture. Also relief of any pressure area and reduction of over xetension in the denture helped in the elimination of pain or ulceration ${ }^{(17)}$. Retention test was performed using NEXYGEN from Lioyd Instrument, which is a universal testing machine with a standardized accurate device for measuring retention. A new attachment was made to help measurement of retention of complete denture in the patient mouth ${ }^{(18)}$.The retention device is very sensitive as when device's sensitivity increases, this increases the device ability to read the smaller values of forces thus giving accurate records. The device has a very sensitive load cell (grade $0.5 \%$ ) that can start measuring from the (0) Newton of force (as the manufacturer claimed) ${ }^{(18)}$. 
The results of this study showed that significant differences between group I, group II and group III denture bases during the follow up study period after one month, highest retention recorded with Conventional denture base lined with soft liner (group II) followed by Co-Cr (group III), while the lowest retention recorded with Conventional denture base (group I). The Retention of conventional denture lined with permanent soft liner was higher than that of the Co-Cr and conventional denture bases after one month this may be attributed to improvement the health of gum tissues by absorbing some of masticatory pressure, help to determine the maximum retention by utilizing undercuts in the bone and gum while hard liners may not able to negotiate the tissue ${ }^{(3)}$.

Using group I and group III denture bases showed statistically significant increase in retention values over than one month this may be attributed to neuromuscular control and patient's adaptability to their dentures, tissue plasticity and mucosal adaptation to any denture base material ${ }^{(3)}$.

Regarding to the Conventional denture base this seemed to compensate for the dimensional changes due to the water sorption, which was definitely associated with some dimensional changes. When these changes happen in an area with variable thickness, they most probably cause distortion, thereby affection the denture adaptation, border seal and retention. This intraoral behavior of the conventional resin was, however, not associated with a decrease in the retention. Instead, the retention continued to increase, but at a slower rate, reflecting the importance of the neuromuscular adaptation of the patient to the denture, tissue plasticity and mucosal adaptation to any denture base material ${ }^{(3)}$.

The Results of group III showed statistically significant increase in retention values over than one month this may be attributed to preservation of remaining residual ridge by optimal distribution of applied load over an increased area, improved patient comfort because of smooth tissue surface, bet- ter support, retention and stability because of close adaptation $^{(19)}$.

When retention values were compared at three months of group III and group I denture bases showed statistically no significant difference this may be attributed to the patients usually function with their prosthesis much better after three months and they become experienced in dealing with it functionally, regardless of the type of prosthesis ${ }^{(20)}$.

\section{CONCLUSION}

The results obtained from this study concluded that the Co-Cr denture base conventional heat cure acrylic resin denture base lined with soft liner material could be used as an alternative treatment modalities for conventional heat cure acrylic resin denture bases in complete edentulous cases suffering from severely resorbed lower ridges.

\section{REFERENCES}

1. Whitmyer C, Esposito S, Alperin S. Longitudinal treatment of a severely atrophic mandible. A clinical report. J Prosthet Dent. 2003; 90:116-120.

2. Rathee D, Goel D, Tamrakar D.Prosthodontic management of severely resorbed mandibular ridge using modified impression technique: A Case Report. Indian J Appl Res. $2013 ; 3: 74-75$.

3. John J, Manappallil. Complete denture prosthodontics, 2nd ed. Arya (Medi) publishing house New Delhi, India. 2011; 129-135.

4. Ajay G, Bhawana T, Hemant G, Himanshu S. Residual Ridge Resorption: A Review. Prosthet Dent.2010; 2: 7-10.

5. Phoenix RD: Denture base resin. Science of dental materials. $11^{\text {th }}$ ed. St louis, Missouri, London. 2003:721-57.

6. Prithviraj D, Singh V, Kumar S, Shruti D.Conservative prosthodontic procedures to improve mandibular denture stability in an atrophic mandibular ridge. J Indian Prosthodont Soc. 2008; 8:178-184.

7. Srdjan DP. Design of complete denture reinforced with metal base. Serbian Dent J. 2013; 60:15-23.

8. Lacoste-Ferre MH, Demont PH, Dandurand J, Dantras F, Duran D, Lacabannec A. Dynamic mechanical proparties of oral mucosa: Comparison with polymeric soft liners. J MechBehav Biomed Mater. 2011; 4:269-274. 
9. Wlodziemerz W, KasperskiJ.The adhesion of modern soft relining materials to acrylic dentures. AdvClinExp Med. 2014; 23:621-625.

10. Quereshy F, Savell T, Palomo J. Applications of cone beam computed tomography in the practice of oral and maxillofacial surgery. J Oral Maxillofac Surg. 2008; 66:791-796.

11. Kummar MV, Bhagath S, Brintha JJ. Historical interest of denture base materials. J Res Dent Sci. 2011; 1:103-105.

12. Menicucci G, Lorenzetti M, Pera P, Preti G. Mandibular implant-retainred overdenture: finite element analysis of two anchorage systems. Int J Oral Maxillofac Implants 1998; 13:369-376.

13. Luis IR, Lenny TS, Patrick WN: The Effect of Using Custom or Stock Trays on the Accuracy of Gypsum Casts. Int J Prosthodont 1996; 9:367-373.

14. Winkler S. Essentials of complete denture prosthodontics. $2^{\text {nd }}$ ed. Saunders WB Co, Philadelphia. 2000; 202.

15. Gehan F. Mohamed.Clinical evaluation of the efficacy of soft acrylic denture compared to conventional one when restoring severely resorbed edentulous ridge. Cairo Dent J. 2008; 24:313-333.

16. Kumar N, Chandra T. Evaluation of variations in composition, corrosion behavior and surface hardness on reusing a Co-Cr-Mo denture alloy. J Indian Prosthodont Soc. 2008; 8: 22-26.

17. Guerrero JS. Use of prophylactic ntibiotic therapy in oral surgical procedures: A critical Review. J Calif Dent Assoc. 2008; 36:943-950.

18. Mohammed A. Clinical evaluation of retention and masticatory efficiency of thermoplastic denture base material. M.D.S. Thesis, AlazharUniveristy. 2010; 7:349.

19. Rastogi I. Management of highly resorbed mandibular ridge. Inter J Dent Health Sci. 2014; 1:512-522.

20. Heckmanns, Winer W, Mayer M and Weber H. Overdenture attachment selection and the loading of implant and denture bearing area. Part 2: A methodical study using five types of attachment. Clin Oral Implants Res. 2001; 12:401-407. 